\title{
Determining the Articles Acceptance Using Logic of Fuzzy Inference System Tsukamoto
}

\author{
Juwita Annisa Fauzia,1,*, Nukleon Jefri Nur Rahman ${ }^{a, 2}$, Anik Nur Handayani ${ }^{\mathrm{b}, 3}$, \\ Abd Kadir Mahamad ${ }^{\mathrm{c}, 4}$ \\ ${ }^{a}$ Graduate School, Universitas Negeri Malang, Malang, Indonesia \\ ${ }^{\mathrm{b}}$ Department of Electrical Engineering, Universitas Negeri Malang, Malang, Indonesia \\ ${ }^{c}$ Faculty of Electrical and Electronic Engineering, Universiti Tun Hussein Onn Malaysia, Batu Pahat, Johor, Malaysia \\ 1 juwita.af@gmail.com; ${ }^{2}$ dr.nukleon@gmail.com; ${ }^{3}$ aniknur.ft@um.ac.id; ${ }^{4}$ kadir@ uthm.edu.my
}

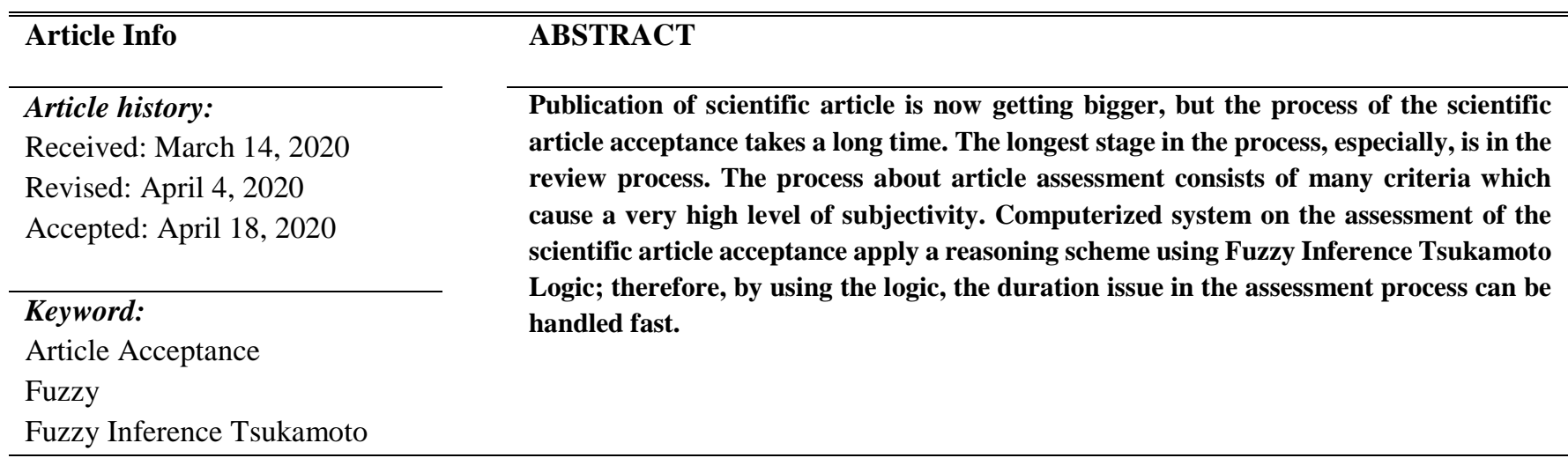

\section{INTRODUCTION}

Scientific article is a strategic medium in the development of academic competence [1]. The scientific article is related to science or findings of new scientific studies in education and knowledge. In the information age, the number of publications of scientific articles describes the quality of human resources that exist in an institution. The qualified institutions of higher education are those that can compete in terms of research. This quality is based on the publication of indexed scientific articles, a means of conveying and disseminating knowledge. The publication system with a scientific approach should be decision-based [2].

The acceptance of scientific articles in an institution is useful to filter the selected articles according to the criteria set by the institution. In general, the process of scientific article acceptance is done through the stages of submitting the article, evaluating by reviewer, announcing the results, revising, editing by related institutions, editing, copyright processing, and publishing. The needs for article publication is getting bigger, but the duration to complete all stages takes a long time. The longest stage is in the reviewers' evaluation. In this case, the article will be recommended to be published, revised, or rejected [3]. Almost all scientific articles use a blind reviewer system. This system does not allow the author to know the identity of reviewers during the review process takes place. Generally, each article will be reviewed by more than one reviewer. Each criterion used by the reviewer depends on the requirements of the institutions of the article publisher. The main problem of the reviewer's assessment cannot be accurately estimated using numeric values [4]. Reviewers will become subjective and judge according to their own styles.

The process of scientific article acceptance is generally online-based. The ease gained only from the platform side when submitting and verifying. The process of scientific article acceptance in the review process is still not efficient. The criteria used in the review stage require a computerized system to solve the duration issue in scientific article acceptance so that it becomes faster. A computerized system of criteria can be done by reasoning method on machine/ computer. This reasoning implements fuzzy logic. Fuzzy logic invented by Prof. Lotfi A. Zadeh in 1965. The basis of fuzzy logic is a theory of fuzzy set [5]. The theory describes that the role of membership function as the determinant of the existence of elements in the set is very important. The membership function becomes the function characteristic of the reasoning using fuzzy logic [6]. The fuzzy logic is associated with exact reasoning [7]. The combination variations of the fuzzy method in terms of inference, aggregation, fuzzification, and defuzzification affect the design of fuzzy systems [8]. 
The Fuzzy function is a generalization of the concept of the old function in which it is a mapping of domain definition to the related function [9]. The fuzzy logic maps an input space to the output one [10]. Fuzzy inference tsukamoto is a form of completion by using fuzzy logic. Fuzzy inference Tsukamoto has two advantages in general [11]. Firstly, it can model criteria by changing the crisp value into linguistic one using fuzzification and then inserting into rules based on knowledge base. Secondly, Fuzzy inference Tsukamoto is relevant to use in real-world problems that mostly use non-linear linguistic values instead of binaries. This article purpose to discussed utilization fuzzy inference Tsukamoto on the determination of scientific article acceptance with three models. The model only shows the comparison of calculation results.

\section{RELATED WORK}

Many problems have been solved by using fuzzy inference tsukamoto, such as in lectures [11], decision making and control [12], and climatology [13]. On the other hand, S. Nazir et al proposed software component selection using fuzzy logic because it could incorporates several important factors [14]. This article incorporates several components to acceptance scientific articles. This article also proposed to remove subjectivity of review process. Subjectivity is uncertainty condition. S. Nazir et al claimed security evaluation model using Fuzzy logic Mamdani inference system helps software engineering during selection in conditions of uncertainty and ambiguity [15]. I. Wahyuni et al proposes Tsukamoto Fuzzy Inference System to predict the rainfall to arrange a good schedule for planting [13]. Method of Tsukamoto Fuzzy Inference System produced better results comparable to those achieved by other method. Fuzzy inference tsukamoto can be used for the determination of the program study in Faculty of Computer Science of Bandar Lampung University, fuzzy inference tsukamoto implemented in giving the recommendation to potential new students in determining the course with their abilities [16]. In medical forum, fuzzy inference tsukamoto used for disease endometritis in cow, the results showed that fuzzy inference tsukamoto work like human expert in diagnosing endometritis [17]. In employment area, fuzzy inference tsukamoto developed in work feasibility, fuzzy inference tsukamoto can be used to provide job classification according to the GPA and APT [18]. Additionally, fuzzy inference tsukamoto used for determining the pieces of tuition fees [11]. Fuzzy inference tsukamoto also using to the decision maker of flood insurance premium determination, according to the results, the amount of premium of income per month affordable for residents [19].

\section{METHOD}

\section{A. Fuzzification}

The methods used in this article is the acceptance of scientific article reasoning using fuzzy logic. This method consists of three phases, namely fuzzification, inference engine, and defuzzification. Fuzzy Inference Tsukamoto applied in defuzzification, while fuzzification and inference engine uses a common phase in the implementation of Fuzzy logic.

Fuzzification is a crisps input value converted into fuzzy input, in the form of linguistic value based on membership function. In this step, crisps inputs cover the values of each input variable consisting of article structure, article content, and plagiarism percentage. Figure 1 shows the fuzzification phase, while Table 1 shows the fuzzy set.

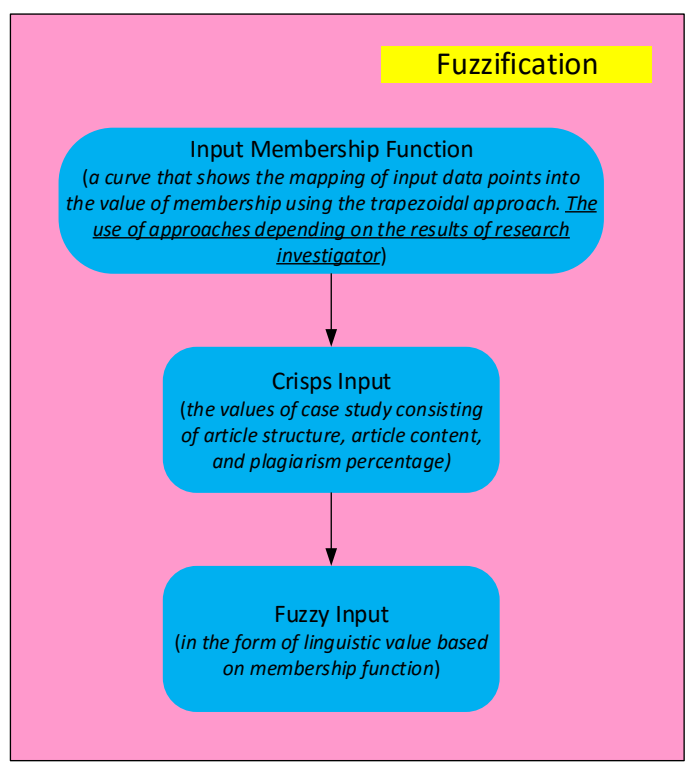

Fig. 1. Fuzzification

TABLE I. FUZZY SET

\begin{tabular}{|c|c|c|c|c|c|}
\hline \multicolumn{6}{|c|}{ Linguistic Variables } \\
\hline \multirow{3}{*}{ Input } & $\begin{array}{l}\text { Structure } \\
\text { Article }\end{array}$ & of & $\begin{array}{l}\text { Poor } \\
\text { Adequate } \\
\text { Good }\end{array}$ & & $\begin{array}{l}>=0-<=30 \\
>=20-<=50 \\
>=40-<=70\end{array}$ \\
\hline & $\begin{array}{l}\text { Content } \\
\text { Article }\end{array}$ & of & $\begin{array}{l}\text { Poor } \\
\text { Adequate } \\
\text { Good }\end{array}$ & & $\begin{array}{l}>=0-<=40 \\
>=30-<=80 \\
>=70-<=100\end{array}$ \\
\hline & $\begin{array}{l}\text { Plagiarism } \\
\text { Article }\end{array}$ & & $\begin{array}{l}\text { Low } \\
\text { High }\end{array}$ & & $\begin{array}{l}>=0-<=15 \% \\
>=10 \%\end{array}$ \\
\hline Output & Article & & $\begin{array}{l}\text { Rejected } \\
\text { Accepted } \\
\text { Revision } \\
\text { Accepted } \\
\text { without } \\
\text { Revision }\end{array}$ & with & $\begin{array}{l}>=0-<=5 \\
>=4-<=9.5 \\
>=9-<=10\end{array}$ \\
\hline
\end{tabular}

The article structure variable is categorized into poor, adequate, and good fuzzy set. Membership function using the trapezoidal approach is shown in Figure 2.

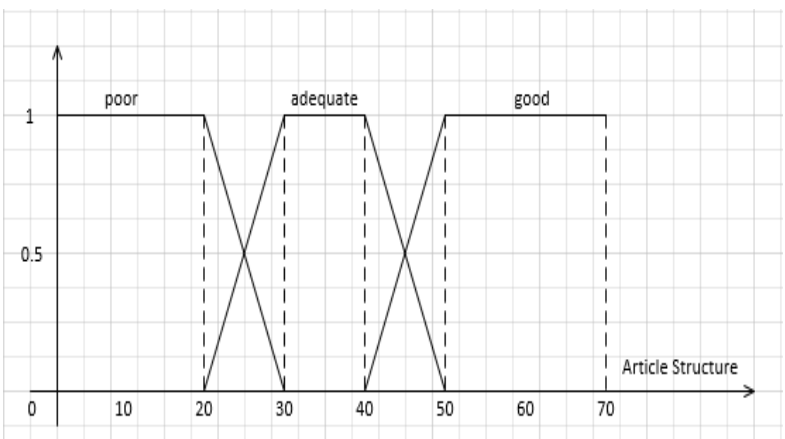

Fig. 2. Membership Function of Article Structure 
Membership Function for variables of Article Structure:

1) Poor structure

нpoor $=\left\{\begin{array}{l}0 ; x \geq 30 \\ \frac{(30-x)}{(30-20)} ; 20 \\ 1 ; x \leq 20\end{array}\right.$

\section{2) Adequate structure}

$\boldsymbol{\mu a d e q u a t e}=\left\{\begin{array}{c}0 ; x \leq 20 \text { atau } x \geq 50 \\ \frac{(x-20)}{(30-20)} ; 20 \leq x \leq 30 \\ \frac{(50-x)}{(50-40)} ; 40 \leq x \leq 50 \\ 1 ; 30 \leq x \leq 40\end{array}\right.$

\section{3) Good structure}

$$
\boldsymbol{\mu g o o d}=\left\{\begin{array}{l}
0 ; x \leq 40 \\
\frac{(x-40)}{(50-40)} ; 40 \leq x \leq 50 \\
1 ; x \geq 50
\end{array}\right.
$$

The article content variables are categorized into poor, adequate, and good fuzzy set. Membership function using the trapezoidal approach is shown in Figure 3.

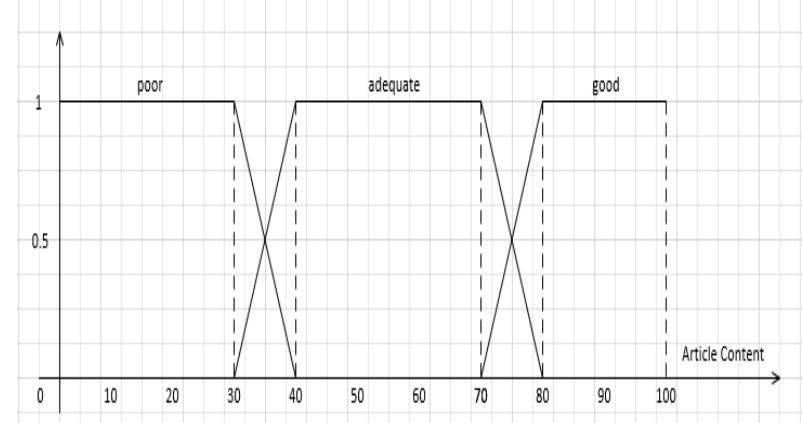

Fig. 3. Membership Function of Article Content

Membership Function for variables of Article Content:

\section{1) Poor content}

$\boldsymbol{\mu p o o r}=\left\{\begin{array}{l}0 ; x \geq 40 \\ \frac{(40-x)}{(40-30)} ; 30 \leq x \leq 40 \\ 1 ; x \leq 30\end{array}\right.$

\section{2) Adequate content}

adequate $=\left\{\begin{array}{c}0 ; x \leq 30 \text { atau } x \geq 80 \\ \frac{(x-30)}{(40-30)} ; 30 \leq x \leq 40 \\ \frac{(80-x)}{(80-70)} ; 70 \leq x \leq 80 \\ 1 ; 40 \leq x \leq 70\end{array}\right.$

\section{3) Good content}

$$
\boldsymbol{\mu} \text { good }=\left\{\begin{array}{l}
0 ; x \leq 70 \\
\frac{(x-70)}{(80-70)} ; 70 \leq x \leq 80 \\
1 ; x \geq 80
\end{array}\right.
$$

Plagiarism variables are categorized into low and high fuzzy set. Membership function using the trapezoidal approach is shown in Figure 4.

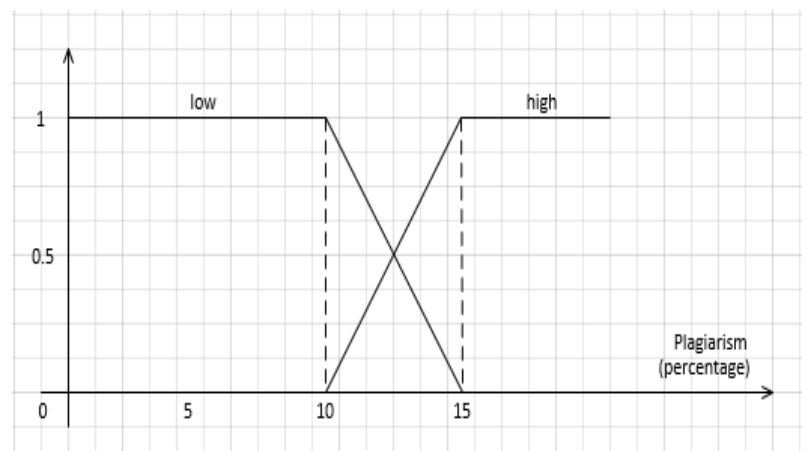

Fig. 4. Membership Function of Plagiarism

Membership Function for Plagiarism variables:

1) Low plagiarism

$$
\boldsymbol{\mu l o w}=\left\{\begin{array}{l}
0 ; x \geq 15 \\
\frac{(15-x)}{(15-10)} ; 10 \leq x \leq 15 \\
1 ; x \leq 10
\end{array}\right.
$$

\section{2) High plagiarism}

$$
\boldsymbol{\mu h i g h}=\left\{\begin{array}{l}
0 ; x \leq 10 \\
\frac{(x-10)}{(15-10)} \\
1 ; x \geq 15
\end{array} 10 \leq x \leq 15\right.
$$

Output article became Journal that contain three condition, Rejected, Accepted with revision, and Accepted without any revision. The membership function of output relate with consequent and inference rules. Membership function output using the trapezoidal approach is shown in Figure 5.

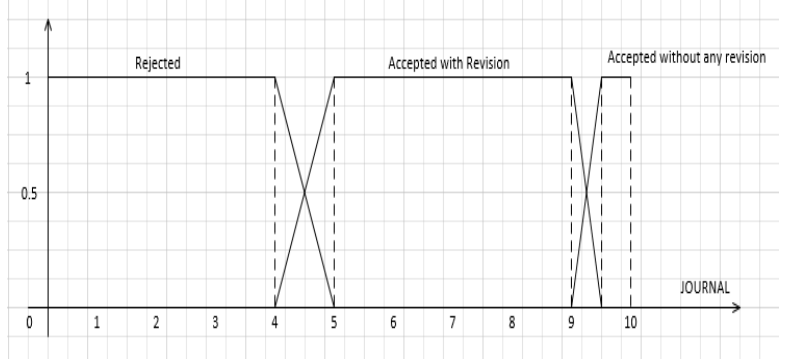

Fig. 5. Membership Output 


\section{B. Inference Engine}

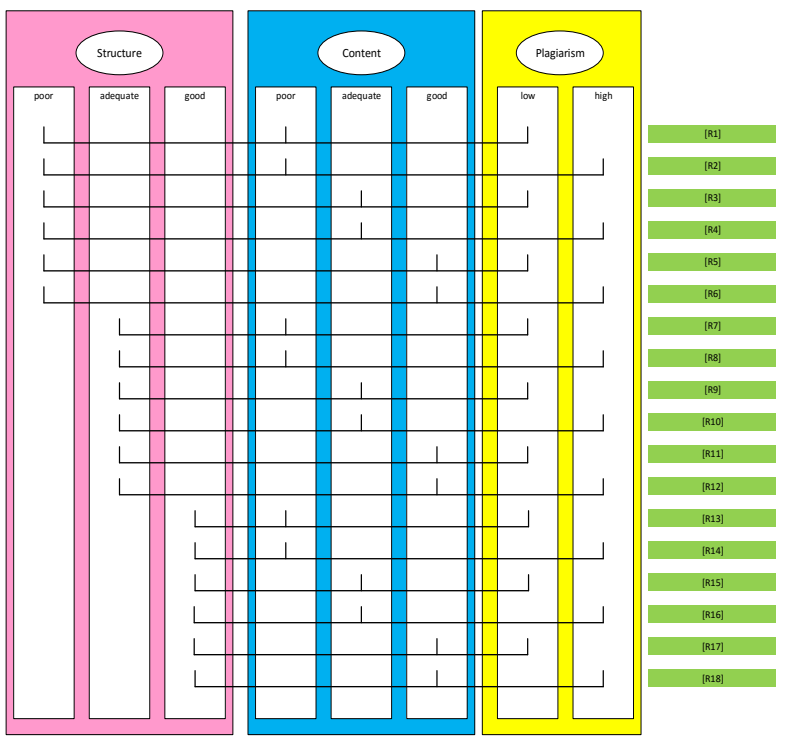

Fig. 6. Inference Rules

Inference engine in determining class categories is by using structure, content and plagiarism variables. The inference engine of the four variables consists of 18 rules which describes in Table 2.

TABLE II. INFERENCE RULES

\begin{tabular}{l} 
Inference Rules \\
\hline [R1] IF (the structure is poor) AND (the content is poor) AND \\
(the plagiarism is low) THEN (the article is rejected) \\
[R2] IF (the structure is poor) AND (the content is poor) AND \\
(the plagiarism is high) THEN (the article is rejected) \\
[R3] IF (the structure is poor) AND (the content is adequate) AND \\
(the plagiarism is low) THEN (the article is accepted with \\
revision) \\
[R4] IF (the structure is poor) AND (the content is adequate) AND \\
(the plagiarism is high) THEN (the article is rejected) \\
[R5] IF (the structure is poor) AND (the content is good) AND \\
(the plagiarism is low) THEN (the article is accepted with \\
revision)
\end{tabular}

[R6] IF (the structure is poor) AND (the content is good) AND (the plagiarism is high) THEN (the article is accepted with revision)

[R7] IF (the structure is adequate) AND (the content is poor) AND (the plagiarism is low) THEN (the article is rejected)

[R8] IF (the structure is adequate) AND (the content is poor) AND (the plagiarism is high) THEN (the article is rejected)

[R9] IF (the structure is adequate) AND (the content is adequate) AND (the plagiarism is low) THEN (the article is accepted with revision)

[R10] IF (the structure is adequate) AND (the content is adequate) AND (the plagiarism is high) THEN (the article is rejected)

\section{Inference Rules}

[R11] IF (the structure is adequate) AND (the content is good) AND (the plagiarism is low) THEN (the article is accepted with revision)

[R12] IF (the structure is adequate) AND (the content is good) AND (the plagiarism is high) THEN (the article is accepted with revision)

[R13] IF (the structure is good) AND (the content is poor) AND (the plagiarism is low) THEN (the article is rejected)

[R14] IF (the structure is good) AND (the content is poor) AND (the plagiarism is high) THEN (the article is rejected)

[R15] IF (the structure is good) AND (the content is adequate) AND (the plagiarism is low) THEN (the article is accepted with revision)

[R16] IF (the structure is good) AND (the content is adequate) AND (the plagiarism is high) THEN (the article is accepted with revision)

[R17] IF (the structure is good) AND (the content is good) AND (the plagiarism is low) THEN (the article is accepted without any revision)

[R18] IF (the structure is good) AND (the content is good) AND (the plagiarism is high) THEN (the article is accepted with revision)

\section{Defuzzification}

Defuzzification is the process of producing a quantifiable result in Crisp logic, given fuzzy sets and corresponding membership degrees. Defuzzification looking for the ultimate value of the output fuzzy. The defuzzification process of a fuzzy set is derived from the composition of fuzzy rules, while the resulting output is a number in the domains of fuzzy set in the form of article acceptance. This program uses a centralized average defuzzification method or so-called center average defuzzifier. The equation formula for the method centroid of area (COA method) defuzzifier is as follows:

$$
z^{*} \frac{a_{1} z_{1}+a_{2} z_{2}+\cdots+a_{i} z_{i}}{a_{1}+a_{2}+\cdots+a_{i}}
$$

\section{RESULT AND DISCUSSION}

Fuzzy logic inference tsukamoto is implemented in three ways of calculation, i.e manual calculation, calculation using matlab, and web-based system. As for each calculation will be comparable using 10 samples of the same case. The detailed description of manual, matlab and web-based systems calculations uses 1 case: an article has a structure value (25), content value (78), and plagiarism (11\%). 


\section{A. Manual Calculation}

Membership Function of the structure values are included in the poor and adequate linguistic values, so:

$$
\begin{aligned}
\text { Apoorstructure }[25] & =\frac{(30-x)}{(30-20)} \\
& =\frac{(30-25)}{(30-20)} \\
& =0.5
\end{aligned}
$$

$$
\begin{aligned}
\text { Madequatestructure }[25] & =\frac{(x-20)}{(30-20)} \\
& =\frac{(25-20)}{(30-20)} \\
& =0.5
\end{aligned}
$$

Membership Function of the content values are included in the adequate and good linguistic values, so:

$$
\begin{aligned}
& \text { } \text { adequatecontent }[78]=\frac{(80-x)}{(80-70)} \\
& =\frac{(80-78)}{(80-70)} \\
& =0.2 \\
& \boldsymbol{\mu} \text { goodcontent }[78]=\frac{(x-80)}{(80-70)} \\
& =\frac{(78-80)}{(80-70)} \\
& =0.8
\end{aligned}
$$

Membership Function of the plagiarism values are included in the low and high linguistic values, so:

$$
\begin{aligned}
& \text { Mlowplagiarism }[11]=\frac{(15-x)}{(15-10)} \\
& =\frac{(15-11)}{(15-10)} \\
& =0.8 \\
& \text { } \boldsymbol{\mu h i g h p l a g i a r i s m}[11]=\frac{(x-10)}{(15-10)} \\
& =\frac{(13-10)}{(15-10)} \\
& =0.2
\end{aligned}
$$

Therefore, rules obtained from the fuzzy input are shown in the Table 3.
TABLE III. CASE CONDITION

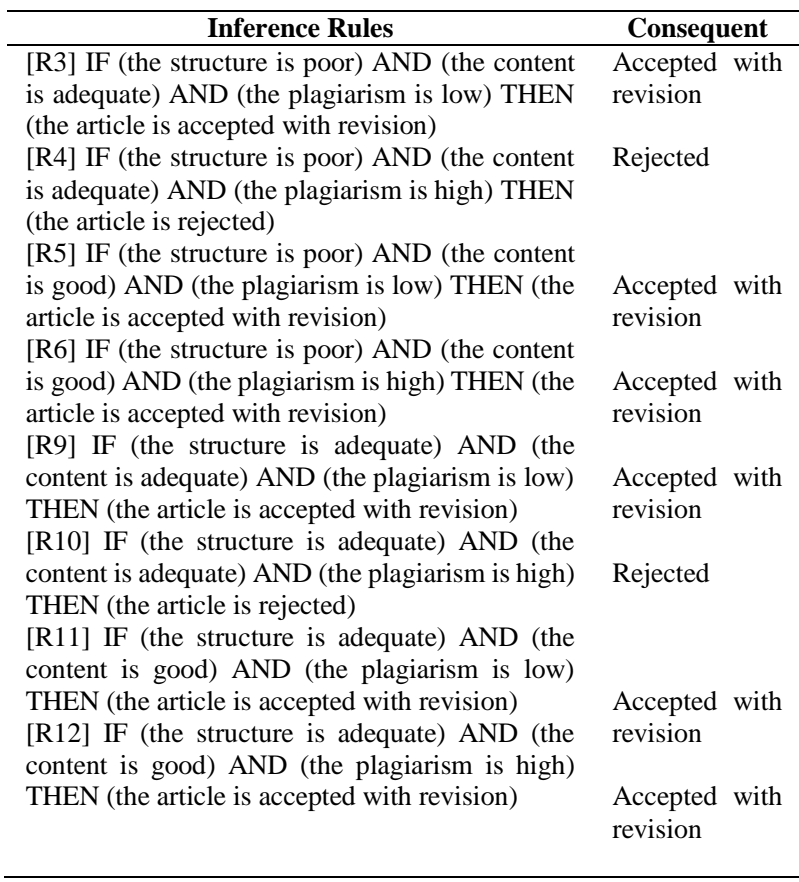

Determining $\alpha$-predicate value based on Rules by using min ( $\mu$ ) minimum value.

- $\alpha$-predicate $3 \quad=\mu$ poor structure $\wedge \mu$ adequate content $\wedge \mu$ low plagiarism

$=\min (\mu$ poor structure $[25] ; \mu$ adequate content [78]; $\mu$ low plagiarism [11])

$$
\begin{aligned}
& =\min (0.5 ; 0.2 ; 0.8) \\
& =0.2
\end{aligned}
$$

- $\alpha$-predicate $4 \quad=\mu$ poor structure $\wedge \mu$ adequate content $\wedge \mu$ high plagiarism

$$
=\min (\mu \text { poor structure }[25] ; \mu
$$
adequate content [78]; $\mu$ high plagiarism [11])

$$
\begin{aligned}
& =\min (0.5 ; 0.2 ; 0.2) \\
& =0.2
\end{aligned}
$$

- $\alpha$-predicate $5=\mu$ poor structure $\wedge \mu$ good content $\wedge \mu$ low plagiarism

$=\min (\mu$ poor structure [25]; $\mu$ good content [78]; $\mu$ low plagiarism [11])

$$
\begin{aligned}
& =\min (0.5 ; 0.8 ; 0.8) \\
& =0.5
\end{aligned}
$$

- $\alpha$-predicate $\_6 \quad=\mu$ poor structure $\wedge \mu$ good content $\wedge \mu$ high plagiarism

$=\min (\mu$ poor structure $[25] ; \mu \operatorname{good}$ content [78] $\mu$ high plagiarism [11])

$$
\begin{aligned}
& =\min (0.5 ; 0.8 ; 0.2) \\
& =0.2
\end{aligned}
$$


- $\alpha$-predicate_9 $=\mu$ adequate structure $\wedge \mu$ adequate content $\wedge \mu$ low plagiarism

$=\min (\mu$ adequate structure $[25] ; \mu$ adequate content [78]; $\mu$ low plagiarism [11])

$$
\begin{aligned}
& =\min (0.5 ; 0.2 ; 0.8) \\
& =0.2
\end{aligned}
$$

- $\alpha$-predicate_10 $=\mu$ adequate structure $\wedge \mu$ adequate content $\wedge \mu$ high plagiarism

$=\min (\mu$ adequate structure $[25] ; \mu$ adequate content [78]; $\mu$ high plagiarism [11])

$$
\begin{aligned}
& =\min (0.5 ; 0.2 ; 0.2) \\
& =0.2
\end{aligned}
$$

- $\alpha$-predicate_11 $=\mu$ adequate structure $\wedge \mu$ good content $\wedge \mu$ low plagiarism

$=\min (\mu$ adequate structure $[25] ; \mu$ good content [78]; $\mu$ low plagiarism [11])

$$
\begin{aligned}
& =\min (0.5 ; 0.8 ; 0.8) \\
& =0.5
\end{aligned}
$$

- $\alpha$-predicate_12 $=\mu$ adequate structure $\wedge \mu \operatorname{good}$ content $\wedge \mu$ high plagiarism

$=\min (\mu$ adequate structure [25]; $\mu$ good content [78]; $\mu$ high plagiarism [11])

$$
\begin{aligned}
& =\min (0.5 ; 0.8 ; 0.2) \\
& =0.2
\end{aligned}
$$

Determining the $\mathrm{z}$ value is done by looking at the consequent of the resulting Inference rules. The calculation uses the article membership output equation by entering the $\alpha$ predicate values. The calculation of Consequent which shows Accepted with Revision is done twice as the article's membership output has complete points namely a, b, c, and d. Whereas the consequents which show Rejected and Accepted without Any Revision only have two points namely each (c and d) and (a and b).

TABLE IV. Z VALUE

\begin{tabular}{llll}
\hline rules & $\boldsymbol{\alpha}$-predicate & \multicolumn{1}{c}{ Consequent } & $\mathbf{z}$ \\
\hline 3 & 0.2 & Accepted with revision & 6.8 \\
4 & 0.2 & Rejected & 4.8 \\
5 & 0.5 & Accepted with revision & 6.9 \\
6 & 0.2 & Accepted with revision & 6.8 \\
9 & 0.2 & Accepted with revision & 6.8 \\
10 & 0.2 & Rejected & 4.8 \\
11 & 0.5 & Accepted with revision & 6.9 \\
12 & 0.2 & Accepted with revision & 6.8 \\
\hline
\end{tabular}

The last calculation is defuzzification.

$Z^{*}=\frac{(0.2)(6.8)+(0.2)(4.8)+(0.5)(6.9)+(0.2)(6.8)+(0.2)(6.8)+(0.2)(4.8)+(0.5)(6.9)+(0.2)(6.8)}{(0.2)+(0.2)+(0.5)+(0.2)+(0.2)+(0.2)+(0.5)+(0.2)}$ $Z^{*}=6.47$

\section{B. Matlab}

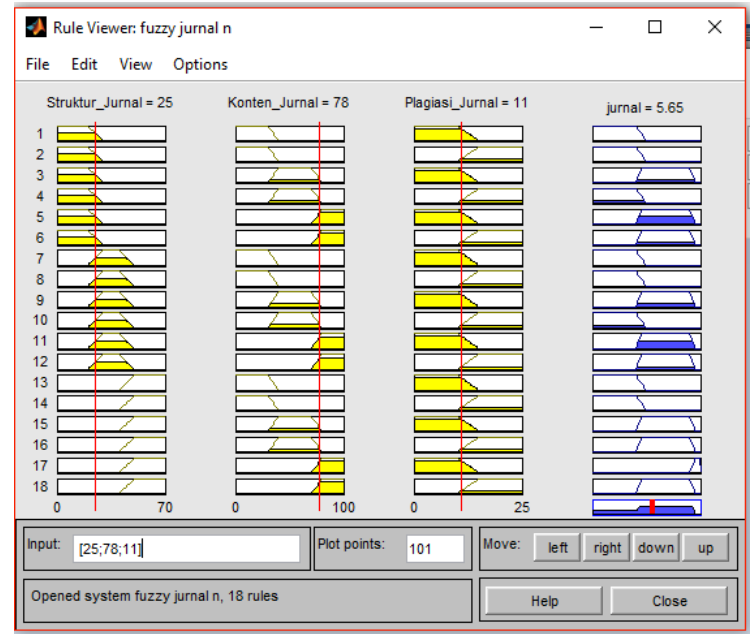

Fig. 7. Results of MATLAB calculation

Matlab calculation is known more precisely than manual calculation; this occurs because the initialization of membership function is directly related to the rules and input cases. In accordance with the same case on manual calculation, the result of article output is 5.65 which means the article is Accepted with Revision.

\section{WEB-Based}

Fuzzy Inference Tsukamoto is applied to a web-based computerized system. The Fuzzy logic is entered into the system. Features in this system consist of 3 input columns i.e Structure, Content, and Plagiarism. Moreover, the system will automatically perform calculations and give results. The system is more complex as it contains the entire rules. Thus, the rules that will be calculated only on rules that match the case entered.

Results on a WEB-based system are accepted with revision. The system does not change the privacy of reviewer in the assessment process. The reviewers are free to express responses from all articles reviewed. They can still provide comments according to their respective styles. The Fuzzy Inference Tsukamoto only plays a role in reducing the duration of the time in the assessment process so that they can more quickly in making decisions. This is in accordance with the criteria of good software development that is, among other things, the fast response from the system, the results of the user response is obtained above $85 \%$ [20], [21].

In this article, 10 same case studies are provided. Manual calculation uses theoretical results. The manual scheme is implemented into the system by providing special privileges according to the rules of the tsukamoto inference. In addition, matlab execution is done because matlab is a medium of the fuzzy logic expert. The results of each calculation can be seen in Table 4, Table 5, and Table 6. S is Structure, C is Content, and $\mathrm{P}$ is plagiarism. 
TABle V. Results of Manual Calculation

\begin{tabular}{|c|c|c|c|c|c|}
\hline \multirow{2}{*}{ Case } & \multicolumn{3}{|c|}{ Input } & \multirow{2}{*}{$\begin{array}{c}\begin{array}{c}\text { Tsukamoto } \\
\text { Method }\end{array} \\
\mathbf{Z}^{*} \\
\end{array}$} & \multirow{2}{*}{$\begin{array}{c}\text { Output } \\
\text { Structure }\end{array}$} \\
\hline & $\mathbf{S}$ & $\mathbf{C}$ & $\mathbf{P}$ & & \\
\hline 1 & 27 & 74 & $13 \%$ & 4.83 & Accepted with Revision \\
\hline 2 & 8 & 35 & $11 \%$ & 5.43 & Accepted with Revision \\
\hline 3 & 20 & 35 & $14 \%$ & 4.43 & Accepted with Revision \\
\hline 4 & 60 & 60 & $11 \%$ & 6.92 & Accepted with Revision \\
\hline 5 & 25 & 75 & $50 \%$ & 5.69 & Accepted with Revision \\
\hline 6 & 25 & 78 & $11 \%$ & 6.47 & Accepted with Revision \\
\hline 7 & 15 & 31 & $14 \%$ & 3.57 & Rejected \\
\hline 8 & 10 & 37 & $14 \%$ & 4.01 & Rejected \\
\hline 9 & 50 & 45 & $12 \%$ & 6.88 & Accepted with Revision \\
\hline 10 & 28 & 72 & $20 \%$ & 5.03 & Accepted with Revision \\
\hline
\end{tabular}

TABLE VI. RESUlTS OF MATLAB CALCULATION

\begin{tabular}{|c|c|c|c|c|c|}
\hline \multirow[t]{2}{*}{ Case } & \multicolumn{3}{|c|}{ Input } & $\begin{array}{c}\text { Tsukamoto } \\
\text { Method }\end{array}$ & \multirow[t]{2}{*}{ Output } \\
\hline & $\mathbf{S}$ & $\mathbf{C}$ & $\mathbf{P}$ & $\mathbf{Z}^{*}$ & \\
\hline 1 & 27 & 74 & $13 \%$ & 4.25 & Accepted with Revision \\
\hline 2 & 8 & 35 & $11 \%$ & 4.62 & Accepted with Revision \\
\hline 3 & 20 & 35 & $14 \%$ & 3.76 & Rejected \\
\hline 4 & 60 & 60 & $11 \%$ & 6.78 & Accepted with Revision \\
\hline 5 & 25 & 75 & $50 \%$ & 4.62 & Accepted with Revision \\
\hline 6 & 25 & 78 & $11 \%$ & 5.65 & Accepted with Revision \\
\hline 7 & 15 & 31 & $14 \%$ & 2.77 & Rejected \\
\hline 8 & 10 & 37 & $14 \%$ & 4.46 & Rejected \\
\hline 9 & 50 & 45 & $12 \%$ & 6.78 & Accepted with Revision \\
\hline 10 & 28 & 72 & $20 \%$ & 5.21 & Accepted with Revision \\
\hline
\end{tabular}

TABLE VII. RESUlts OF WEB CALCULATION

\begin{tabular}{|c|c|c|c|c|c|}
\hline \multirow[t]{2}{*}{ Case } & \multicolumn{3}{|c|}{ Input } & $\begin{array}{l}\text { Tsukamoto } \\
\text { Method }\end{array}$ & \multirow[t]{2}{*}{ Output } \\
\hline & $\mathbf{S}$ & $\mathbf{C}$ & $\mathbf{P}$ & $\mathbf{Z}^{*}$ & \\
\hline 1 & 27 & 74 & $13 \%$ & 4.34 & Accepted with Revision \\
\hline 2 & 8 & 35 & $11 \%$ & 5.23 & Accepted with Revision \\
\hline 3 & 20 & 35 & $14 \%$ & 4.89 & Accepted with Revision \\
\hline 4 & 60 & 60 & $11 \%$ & 5.25 & Accepted with Revision \\
\hline 5 & 25 & 75 & $50 \%$ & 6.17 & Accepted with Revision \\
\hline 6 & 25 & 78 & $11 \%$ & 5.41 & Accepted with Revision \\
\hline 7 & 15 & 31 & $14 \%$ & 3.87 & Rejected \\
\hline 8 & 10 & 37 & $14 \%$ & 3.96 & Rejected \\
\hline 9 & 50 & 45 & $12 \%$ & 5.62 & Accepted with Revision \\
\hline 10 & 28 & 72 & $20 \%$ & 5.33 & Accepted with Revision \\
\hline
\end{tabular}

The average manual calculation is 5.35 , the average matlab calculation is 4.89 , and the average system calculation is 5.00 . Comparisons between system and matlab is $2 \%$, system and manual is $6 \%$, and matlab and manual is $9 \%$. Comparisons of the three calculation models are done to see the level of manual theoretical accuracy. Based on these results, the comparative rate of each calculation is less than $10 \%$. Therefore, the use of fuzzy inference logic tsukamoto can be implemented on the acceptance of scientific articles with various criteria.

\section{CONCLUSION}

Scientific article acceptance that uses calculations with various criteria can implement the logic of Fuzzy Inference Tsukamoto. Fuzzy Inference Tsukamoto calculated on three media i.e manual, matlab, and web based system to shows the comparison of calculation results. The comparative rate of each calculation is less than $10 \%$. This reasoning can reduce time issue and long duration in the assessment process. In addition, scientific article acceptance using Fuzzy Inference Tsukamoto can be developed according to the needs of each institution.

\section{References}

[1] A. Z. Mansor, "Reflective learning journal using blog," Procedia-Social Behav. Sci., vol. 18, pp. 507-516, 2011.

[2] R. Vogel, F. Hattke, and J. Petersen, "Journal rankings in managemen and business studies: What rules do we play by?," Res. Policy, vol. 46, no. 10, pp. 1707-1722, 2017.

[3] L. Bornmann and H. D. Daniel, "Selecting manuscripts for a high-impact journal through peer review: A citation analysis of communications that were accepted by Angewandte Chemie International Edition, or rejected but published elsewhere," J. Am. Soc. Inf. Sci. Technol., vol. 59, no. 11, pp. 1841-1852, 2008

[4] Z. Turskis and E. K. Zavadskas, "A new fuzzy additive ratio assessment method (ARAS-F). Case study: The analysis of fuzzy multiple criteria in order to select the logistic centers location," Transport, vol. 25, no. 4, pp. 423-432, 2010.

[5] L. A. Zadeh, "A fuzzy Set Theoretical Interpretation of Linguistic," Hedges J. Cybern., vol. 2, pp. 4-34, 1972.

[6] S. Sebastian and J. Philip, "I-Fuzzification of Fuzzy Sets," J. Chem. Biol. Phys. Sci., vol. 4, no. 3, pp. 2519-2523, 2014.

[7] G. C. Hazarika and T. Bora, "Fuzzification of Bisection Method," Int. J. Sci. Res., vol. 4, no. 1, 2015

[8] R. K. Nowicki and J. T. Starczewski, "A new method for classification of imprecise data using fuzzy rough fuzzification," Inf. Sci. (Ny)., vol. 414, pp. 33-52, 2017.

[9] H. J. Zimmermann, Fuzzy Set Theory and Its Applications, 4th ed. New York: Springer, 2001

[10] F. Klawonn, R. Kruse, and R. Winkler, "Fuzzy clustering: More than just fuzzification," Fuzzy sets Syst., vol. 281, pp. 272-279, 2015.

[11] M. Iswan, W. Fitriani, N. Mayasari, and A. P. U. Siahaan, "Tuition Reduction Determination Using Fuzzy Tsukamoto," Int. J. Eng. Sci. Inven., vol. 5, no. 9, pp. 68-72, 2016.

[12] S. Chaudhari, M. Patil, and J. Bambhori, "Study and review of fuzzy inference systems for decision making and control," Am. Int. J. Res. Sci. Technol. Eng. Math., vol. 14, no. 147, pp. 88-92, 2014.

[13] I. Wahyuni, W. F. Mahmudy, and A. Iriany, "Rainfall prediction in Tengger region Indonesia using Tsukamoto fuzzy inference system," in 1st International Conference on Information Technology, Information Systems and Electrical Engineering (ICITISEE), 2016, pp. 130-135.

[14] S. Nazir, M. A. Khan, S. Anwar, H. Khan, and M. Nazir, "A novel fuzzy logic based software component selection modeling," in International Conference on Information Science and Applications, 2012, pp. 1-6.

[15] S. Nazir, S. Shahzad, S. Mahfooz, and M. Nazir, "Fuzzy logic based decision support system for component security evaluation," Int. Arab J. Inf. Technol., vol. 15, no. 2, pp. 224-231, 2018.

[16] F. Ariani and R. Y. Endra, "Implementation of fuzzy inference system with Tsukamoto method for study programme selection," in International Conference on Engineering and Technology Development (ICETD), 2013, pp. 189-200.

[17] A. Nugroho, "Mobile expert system using fuzzy tsukamoto for diagnosing cattle disease," Procedia Comput. Sci., vol. 116, pp. 27-36, 2017.

[18] M. I. Perangin-Angin, A. H. Lubis, I. S. Dumayanti, R. B. Ginting, A. Putera, and U. Siahaan, "Implementation of Fuzzy Tsukamoto Algorithm in Determining Work Feasibility," J. Comput. Eng, vol. 19, no. 4, pp. 52 $55,2017$.

[19] B. Subartini et al., "Fuzzy inference system of tsukamoto method in decision making on determination of insurance premium amount for due damages of flood natural disaster," J. Fundam. Appl. Sci., vol. 10, no. 1S, pp. 79-94, 2018.

[20] H. Elmunsyah, H. Suswanto, K. Asfani, and W. Hidayat, "The effectiveness of plagiarism checker implementation in scientific writing 
for vocational high school," in International Conference on Indonesian

Technical Vocational Education and Association (APTEKINDO 2018),

2018, pp. 192-196.

[21] A. S. Pratiwi, D. A. Sudjimat, and H. Elmunsyah, "Contribution of industrial work practice performance and creativeness to the academic skill and its effect to the outcome of skill competency test of computer and network technology skill package in vocational high school," ournal Educ. Vocat. Res., vol. 7, no. 4, pp. 31-36, 2016. 